ARTICLE

https://doi.org/10.1057/s41599-019-0288-8

\title{
Does climate opportunity facilitate smallholder farmers' adaptive capacity in the Sahel?
}

\author{
Richard Lalou', Benjamin Sultan², Bertrand Muller ${ }^{3} \&$ Alphousseyni Ndonky ${ }^{4}$
}

\begin{abstract}
In Africa, adaptation will be crucial to offset expected negative climate change impacts on food security and agriculture development. In this study, we combine meteorological data from 18 local stations, field surveys on agricultural practices and agronomic information on the growth of millet to demonstrate the crop suitability to the present climate and the ability of Senegalese farmers to adapt their practices to climate variability, and to disseminate them. From data collected in both 665 villages and 1061 farmers, our study provides quantitative evidence of the responsive adaptation of farmers in the Sahel where the recent resumption of rainfall has provided new agricultural opportunities. Statistical models and cropping simulations show that these farmers innovate by reintroducing and disseminating a long cycle millet cultivar-more suitable for wet environments. We note that although this adaptation is a clear response to recent changes in quantity and distribution of rainfall, its adoption remains limited (50\% of the villages visited and $25 \%$ of the surveyed agricultural producers have cultivated the new millet variety) and varies strongly within the same climatic context and by characteristics of farmers (willing and capacity), indicating different agricultural strategies (diversification, market exchanges). If land access and development of cash crops are hindrances to the adoption of sanio, poverty is clearly not a barrier and adaptation is not a lever for wealth creation. Such adaptative capacities, together with government incentives for farmers to sustainably adapt to climate change, can be important in reducing climate risks in the coming years.
\end{abstract}

\footnotetext{
${ }^{1}$ MERIT, Université de Paris, IRD, F-75006 Paris, France. ${ }^{2}$ ESPACE-DEV, Univ Montpellier, IRD, Univ Guyane, Univ Réunion, Univ Antilles, Univ Avignon, 500 rue Jean-François Breton, F-34093 Montpellier Cedex, France. ${ }^{3}$ UMR AGAP, CIRAD/INRA/SupAgro, 34398 Montpellier, France. ${ }^{4}$ LPED, Aix-Marseille Université, IRD, Campus International UCAD/IRD, Dakar, Senegal. Correspondence and requests for materials should be addressed to R.L. (email: richard. lalou@ird.fr)
} 


\section{Introduction}

ome evidence show that agriculture will be more affected by climate change in Africa than in other regions of the world (Sultan and Gaetani, 2016; Knox et al., 2012; Roudier et al., 2011, Rippke et al., 2016). Smallholder agriculture, the most widespread across Africa, has long been characterised by adaptive and flexible strategies to reduce vulnerability to climate natural variability and soil depletion (Adger et al., 2003, Tschakert, 2007; Eriksen et al., 2008; Thomas et al., 2007). African farmers, particularly in dry land areas, have developed both on- and off-farm adaptation strategies in response to these risks. These are based on four principles: (i) diversification (crops and farming/nonfarming activities); (ii) association (different crops on the same field, mixed crop-livestock farming, cultivated/natural spaces); (iii) intensification (labour resources and soil fertility); and (iv) species selection (based on natural conditions and population needs) (Agrawal, 2010). These adaptative strategies have aimed to offset the negative impacts of natural climatic variations and shocks, including droughts, and sustain the agroecosystem, whenever possible, without changing its fundamental attributes (Malik et al., 2010; Parry et al., 2007; Fankhauser et al., 1999).

In the context of climate change in Sahel, these adaptations often had limited impacts and mostly amounted to survival strategies for farmers with no possibility of increased agricultural production. When facing climate-related shocks, resource-poor farmers adopt erosive coping strategies for agriculture, whose long-term impacts are negative on household productivity (Kates et al., 2012; Rickards and Howden, 2012), and/or develop migration strategies (Suhrke, 1994; Findley, 1994; Henry et al., 2004; Lalou and Delaunay, 2017). Thus, if climate shocks require agricultural adaptation strategies from African smallholder farmers, they hinder these adaptations rather than favour them. Climate change can also create agricultural opportunities and farmers can develop strategies to take advantage of them (IPCC, 2014). Unlike shocks, climatic opportunities, such as a rise in rainfall, are likely to increase available natural resources without diminishing household economic capacities. Hence, the question raised in this study is to determine whether climate opportunity is likely to facilitate adaptation of vulnerable agrarian societies.

Just as the relationship between rainfall quantity and crop growth cannot be reduced to a simple causal association (Adejuwon, 2005), climate opportunity and adaptation are linked by interactive and mediatized mechanisms through many factors that drive the adaptative strategy (Mertz et al., 2009; BerrangFord et al., 2011; Huq and Reid, 2004; Smit and Wandel, 2006; Kristjanson et al., 2012). Farmers' adaptation to climate opportunity results from the combination of necessary conditions, ancestral know-how, and economic and bioecological utilities. We aimed at establishing the causal link between a climatic factor (the increase in rainfall) and the recurrence of a variety of longcycle millet (adaptation strategy), describing the spread of longcycle millet cropping and understanding the determinants of this strategy. To this end, we analysed meteorological, agronomic and socioeconomic databases, collected at different multidecadal timeframes (1950-2015; 1997-2015) in 665 villages and 1061 farms in West Africa across scales (across individuals, farms and villages).

We focused on the old groundnut basin area in Senegal that is characterised by a recent increase in annual rainfall and the reappearance of a long-cycle millet. The study zone (yellow in Fig. 1a) is situated $135 \mathrm{~km}$ east of Dakar, lying mainly in the department of Fatick (the Fatick region) and extending into the regions of Thies in the West and Diourbel in the North. It also includes the Niakhar Health and Demographic Surveillance System (HDSS-Niakhar) (green in Fig. 1a), a long-running health and demography surveillance system, which is made up of 30 villages in large majority sereer across 203 square kilometres within the continental Sahel-Sudan climate zone.

The objective of this study is to determine whether a climate opportunity can help farmers to adapt and pave the way for agriculture transformation. We use four databases-meteorological, agronomic, geographic and socio-behavioural-for the various analyses described in the Method section (spatial and temporal correlation models, event coincidence analysis, agronomic simulation and logistic regression). Regarding the results, we show first that decade-long trend of rainfall is very well perceived by farmers, who quickly responded using some adaptive strategies. Second, based on statistical analyses and crop modelling studies, we demonstrate that some farmers are better able to adapt by reintroducing a long-cycle cultivar of millet (sanio), that was abandoned because of the lengthy drought in the 1980s and which is suitable to current weather conditions. Finally, we discuss the determinants of this adaptation strategy and its ability to transform agriculture into the region.

\section{Methods}

Data collection. All the databases used in the analyses presented in the previous sections are described in Table 1. Overall, the data used, are of two types:

- Time series of data collected in routine (meteorological data, agronomic data and population data of HDSS-Niakhar). They are generally exhaustive for the covered geographical area and they describe a pluri-decadal evolution.

- Declarative and retrospective agricultural survey data (data on agricultural practices and on the spatial distribution of villages cultivating the sanio). These databases are sometimes exhaustive, sometimes representative (random sample).

To understand the dynamics of the reappearance and distribution of sanio in the study zone we questioned rural populations in all of the villages listed in the territory (usually including the village chief) using a questionnaire with approximately fifteen questions. The questions covered: (i) the use of sanio in the 2015 rainy season; (ii) the year this grain reappeared in the village; (iii) the advantages and drawbacks of growing sanio and (iv) the presence and number of farmers who had never stopped growing this variety. The geographic coordinates of the village centre were taken using GPS. This light survey was conducted between April and August 2015 and gathered information on sanio growing practices from 665 villages in our study zone.

To learn more about the social and agricultural rationales and motivations behind Sereer farmers' decisions whether or not to plant sanio, we conducted a survey in 30 villages in the HDSSNiakhar and in 1061 family farms (32\% of the households in these villages). Two questionnaires were administered at each farm. One was a "household" questionnaire, administered to the head of household, which revealed the crop system used during the 2013 rainy season and included over 45 questions about sanio and souna millet cultivation. A "farmer" questionnaire was then administered to a randomly selected farmer in the household, which covered which crops were intended for sale, such as peanuts and watermelon, or for livestock fattening. Other questions addressed perceptions of the climate today and in the past, and on knowledge of climate change. The survey was conducted from December 2013 to March 2014.

Finally, questionnaire-based surveys were supplemented by several focus groups and individual interviews. These helped further our understanding of the decision-making processes and motivations both for and against planting sanio. The focus groups 

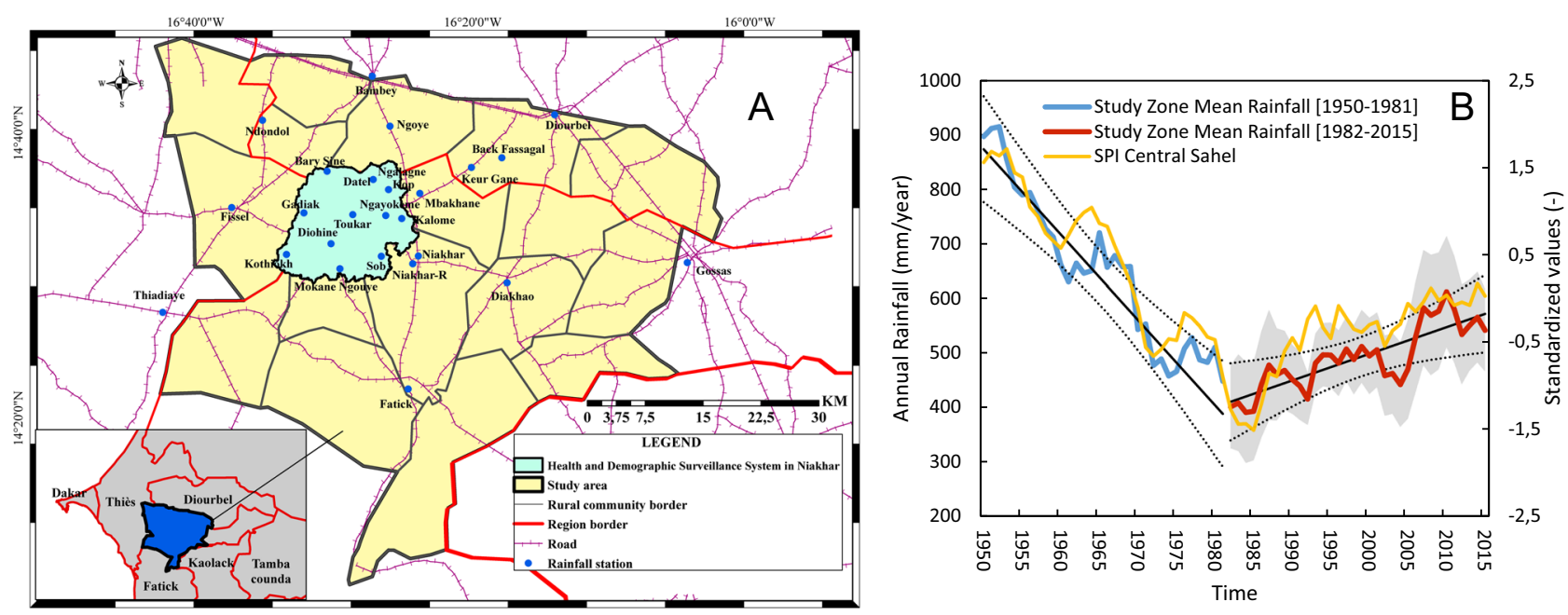

Fig. 1 Map of the study zone (a) and Annual rainfall evolution (b). Average annual rainfall from 1950 to 2015 in the study zone (blue and red lines). Due to data availability, the time series is based on an average of two stations (Bambey and Fatick) from 1950 to 1981 (blue line) and an average of 18 stations from 1982 to 2015 (red line). The location of the stations is shown on the left map. The black line shows the linear trend over the two-time periods with a 95\% confidence interval. The grey shaded area represents values included within 1 standard deviation of the mean of the 18 stations between 1982 and 2015. The yellow time series on the right axis represents the standard precipitation index computed from 43 stations in Central Sahel published by Panthou et al. (2014). A five-year moving average has been applied to all time series to remove high-frequency variability

Table 1 Description of the databases used in the study

\begin{tabular}{|c|c|c|c|}
\hline \multirow{2}{*}{$\begin{array}{l}\text { Characteristics } \\
\text { Data type }\end{array}$} & \multicolumn{3}{|l|}{ Databases } \\
\hline & Weather data & Agronomic data & $\begin{array}{l}\text { Spatial distribution data } \\
\text { on sanio }\end{array}$ \\
\hline Responsible services & $\begin{array}{l}\text { - ANACIM (Senegal) } \\
\text { - CIRAD (France) } \\
\text { - IRD (France) }\end{array}$ & - CIRAD (France) & $\begin{array}{l}\text { - CIRAD (France) } \\
\text { - IRD (France) }\end{array}$ \\
\hline Subject/Description & $\begin{array}{l}\text { Time series of rainfall (annual } \\
\text { cumulation) }\end{array}$ & $\begin{array}{l}\text { Crop model simulations of } \\
\text { biomass and yields of souna and } \\
\text { sanio millet }(\mathrm{kg} / \mathrm{ha})\end{array}$ & $\begin{array}{l}\text { Declarative data on the } \\
\text { cultivation of sanio in the } \\
\text { villages-History of the } \\
\text { cultivation of sanio ( } 16 \\
\text { questions) in the } \\
\text { community. }\end{array}$ \\
\hline
\end{tabular}

Collection

Number of

observations

Representativeness

20 collection points followed up for 65 years

Completeness

Method

Methods of analysis

Time coverage

Space coverage
Annual yields and biomass from 1950 to 2015

The simulation is representative at the plot scale at the Bambey station but similar patterns were found using the data of the Diourbel meteorological station. Simulations of crop yields and above-ground biomass of souna and sanio millet were performed using the SARRA-H crop model at the Bambey location.

Trend and correlation analyses (Fig. 5)

1950-2015

At the plot scale at Bambey location
665 villages surveyed, of which 346 had cultivated sanio before 2015

Completeness

Key informant survey, faceto-face

Analysis of the spatial (Fig. 2a, b)

1997-2015

All villages in the study area (See Fig. 1a) diffusion of sanio crop
Daily reports of precipitation from meteorological and synoptic stations (Diourbel and Bambey) and rain gauges (18 other sites)

Trend (Fig. 1b), correlation

(Fig. 3) and Event coincidence (Fig. 4) analyses

\section{0-2015}

20 collection stations spread over the Fatick region and in the frontier areas with the Diourbel and Thiès regions. (See Fig. 1a)
Farming pratice data - IRD

(France)

- Routine data from the Health and Demographic Surveillance System (HDSS-Niakhar)

- Survey data on the functioning of farms and on the cropping system

1061 surveyed farmers

Simple random draw, proportional to village size (survey rate: 1061/ $3265,32.5 \%$ )

Survey of farmers, face-toface

Analysis of the factors associated with the cultivation of sanio by logistic regression model 2013-2014

All 30 villages of HDSSNiakhar (See Fig. 1a) 
were also an opportunity to collect information on the history of sanio cultivation in the villages, whether it continued to be planted during the dry season, and how common it was among the rural Sereer population and across this territory. The main focus groups took place in the villages of Sob (March 2012), Ngayokhem (November 2013 and October 2014), and Keur Ngane (November 2013).

\section{Agronomic simulation}

Crop model description. We used the process-based crop model SARRA-H Version 32 developed by CIRAD which is particularly suited for the analysis of climate impacts on cereal growth and yield in dry tropical environments (Sultan et al., 2013; Sultan et al., 2014; Dingkuhn et al., 2003; Baron et al., 2005; Sultan et al., 2005). The crop model simulates yield attainable under waterlimited conditions by simulating the soil water balance, potential and actual evapotranspiration, phenology, potential and waterlimited assimilation, and biomass partitioning (Kouressy et al., 2008 for a detailed review of model concepts). The inputs to the model are daily weather data, latitude, soil depth, soil water content capacity, mulches if any, sowing density and depth, and a series of crop parameters. The water balance simulates runoff using a rain event empirical threshold of $20 \mathrm{~mm}$ (Mishra et al., 2008), soil evaporation, storage, deep drainage, transpiration and soil surface evaporation. The soil is divided into a $200 \mathrm{~mm}$ top layer used to simulate evaporation and a layer of variable thickness representing the wetted zone. Water holding capacity of the soil between wilting point ( $\mathrm{pF}=4.2)$ and field capacity $(\mathrm{pF}=3.0)$ is calibrated from available soil data and is set to $100 \mathrm{~mm} \mathrm{~m}^{-1}$ for this study to represent a sandy soil, which is typical of the major millet-producing soils in West Africa (Bationo et al., 2005). The root front, which descends at empirical rates depending on the growth stage, follows the wetting front but is also limited by it. The maximum root depth is fixed at $1800 \mathrm{~mm}$. Water extraction from the soil consists of two additive components, surface evaporation and extraction from the root zone through transpiration. Potential carbon assimilation rates are obtained by multiplying intercepted photosynthetically active radiation, calculated according to the Beer-Lambert law, with an empirical conversion efficiency coefficient that is analogous to radiation use efficiency (Sinclair and Muchow, 2000) but based on assimilation before subtracting respiration losses. After subtraction of a temperature and biomass dependent maintenance respiration (Penning de Vries et al., 1989), biomass is partitioned during the vegetative stage among roots, stems and leaves according to empirical allometric rules. Leaf biomass is converted to leaf area index (LAI) from dynamically simulated specific leaf area (SLA) (Penning de Vries et al., 1989). Grain filling is simulated to capture the influence of the environment on harvest index by determining sink capacity during pre-floral stages and inducing leaf senescence after flowering when sink capacity exceeds current assimilation rates by decreasing leaves and stem biomass. The phenology is based on simplified concepts of successive phases: basic vegetative phase, photoperiod-sensitive phase (PSP), reproductive phase, flowering and grain filling phase and maturation phase which ends with grain maturity. PSP depends on both temperature and astronomic day length and the other phases have constant (genotypic) thermal duration (Dingkuhn et al., 2008). Daily observed minimum and maximum temperatures are used for the calculation of thermal time depending on temperature thresholds (Dingkuhn and Miezan, 1995).

Crop model calibration and validation. Trials were used to calibrate the model to farmers' varieties (souna 3 and sanio) by adjusting model parameters such as phenological stages, sums of temperature, photoperiod sensitivity coefficients, biomass partitioning coefficients and potential grain yields. These trials were carried out at the Bambey research station of ISRA (Senegal Agricultural Research Institute) in 2008 (Kouakou et al., 2013). Independent data from trials conducted in the same site (1996-1999 for souna 3, 2012 for sanio; see Kouakou et al., 2013) were used to validate the model. These experiments included different plots under varying levels of water supply, but under constantly high nutrient supply and no significant biotic stresses. The performances of the model were assessed using the two following indicators applied to yield estimates at harvest as follows:

\section{Relative Root Mean Square Error : RRMSE}

$=\left(\sum_{i=1}^{n}(P i-O i)^{2} / n\right)^{1 / 2} / \bar{O}$

$$
\begin{aligned}
& \text { Index of Agreement : IA } \\
& =1-\left(\sum_{i=n}^{n}(P i-O i)^{2} / \sum_{i=n}^{n}(|P i-\bar{O}|+|O i-\bar{O}|)^{2}\right)
\end{aligned}
$$

where $\mathrm{Pi}=$ predicted value, $\mathrm{Oi}=$ actual value, $\overline{\mathrm{O}}=$ average of the actual values, $n=$ number of cases considered (Willmott, 1982). As the performance of a model increases, RRMSE and IA tend respectively towards $0 \%$ and 1 . After calibration of souna 3 variety, the values of RRMSE (Eq. 1) and IA (Eq. 2) were $36 \%$ and 0.76 , respectively. RRMSE and IA reach $19 \%$ and 0.63 , respectively, after the calibration of sanio. More details on these calibration and validation steps can be found in Kouakou et al. (2013).

In this study, we used SARRA-H to simulate crop yields of both souna 3 and sanio over the 1950-2015 period. The simulation was done at the Bambey location, which was the only site in our surveyed area with all the necessary daily weather data to force the crop model (rainfall, global radiation, surface wind speed, humidity, and minimum, maximum and mean temperature).

Statistical analysis. Rainfall trends were evaluated using data from rainfall measurement stations and from three meteorological stations set up by ANACIM (National Meterology Agency), ISRA (Senegal Institute for Agronomic Research) and IRD (French Research Institute for Development). Our study zone was covered by a total of 26 sites measuring rainfall, including 18 in the HDSS-Niakhar. Geostatistical analyses and mapping representations were produced using ArcGIS Esri ${ }^{\mathrm{TM}}$ 10.5 .

- The rainfall measurements come from the Bambey and Diourbel meteorology stations and from average total rainfall data from 18 stations in the HDSS-Niakhar (See Table 1).

- The density surface area of villages that had started growing sanio again was obtained from a raster grid that combined the point density at each pixel with nearby points. We combined three methods to statistically limit the geographic sanio zones by the degree of village sanio cultivation-standard deviational ellipse, point density, and hierarchical neighbourhood clusters-and thus defined three distinct areas in the study zone: one with a high concentration in the centre, one with a very low presence of long-cycle millet in the north, and one with a fairly low presence of the grain in the south.

The study of the dynamic interdependencies between different observational time series is made by the traditional correlation analysis and by the event coincidence analysis, which takes the timings of events of two series into account (Donges et al., 2016; Rammig et al., 2015; Sigmund et al., 2016a and 2016b). 
- The correlation between the amount of annual rainfall and the renewed cultivation of sanio is based on the estimate of rainfall within each of the three defined areas. Using rasterformat files generated by spatial interpolation of the observed data (standard kriging), the average annual rainfall was estimated for every year from 1998 to 2015 and in the three vector-format polygonal areas that represent the degree of sanio cultivation. Once the three rainfall measurement series were obtained, we looked for the best fractional polynomial of annual rain accumulation to define the polynomial function that fits the incidence level of villages adopting sanio with annual rainfall. This function is:

$$
f(x)=\sum_{i=1}^{k} \gamma x^{P i}+\varepsilon
$$

The degrees of the polynomial function (Eq. 3) were tested at all strengths using the group $P=\{-2,-1,-0.5,0,1,2,3,4\}$, where $p^{0}$ becomes $\ln (p)$. More generally, third degree equations were adequate to obtain a good fit. The model that best fit the data was selected using the AIC criterion. All calculations were performed using STATA ${ }^{\circledR} 13.1$ (2014; Stata Corporation, College station, Texas, USA).

- The event coincidence analysis (ECA) is a method to quantify the simultaneity of events contained in two series of observations, as lagged coincidence within a user-specific temporal tolerance window. The method is particularly effective in highlighting threshold effects, which can be produced by extreme events. Thus, the two time series of data on rainfall (event $\mathrm{A}$ ) and on the adoptive villages of the sanio crop (event B) have been defined with a binary structure (event/no event) and in relation to a threshold beyond which event $A$ triggers the event $B$, in proportions that strongly deviate from the average (e.g.: 65th percentile). As part of this study, we analysed the trigger coincidence rates, calculated from the CoinCalc package, an open-source software package written in the programming language $\mathrm{R}$ by J. Sigmund (Sigmund et al., 2017). The trigger coincidence rate is:

$$
r_{t}(\Delta T, \tau)=\frac{1}{N_{A}} \sum_{i=1}^{N_{A}} \theta\left[\sum_{j=1}^{N_{B}} 1_{[0, \Delta t]}\left(\left(t_{i}^{A}-\tau\right)-t_{j}^{B}\right)\right]
$$

where $r_{t}(\Delta T, \tau)$ measures the fraction of $\mathrm{B}$ type events that are followed by at least one A-type event (Donges et al., 2016). The statistical significance of trigger coincidence rate is based on the calculation of event coincidence analysis for a large number of randomly shuffled time series having the same number of events like the original time series ("shuffle.surrogate").

The ECA approach is appropriate for a naive conception of causality, in the sense given to it by physics: the cause precedes the effect, but is not appropriate to causality considered predictive (in the sense of C. Granger).

The explanatory model of sanio cultivation was constructed using data from the questionnaire survey together with information collected on a routine basis at the HDSS-Niakhar. To show that increased rainfall is a necessary but not sufficient condition for growing sanio in the region, we evaluated the effects of farmer and farming practice characteristics on the use of this grain. The individual and household variables incorporated into the model were: farmer's gender, farmers' perception of the climate today, previous practices of sanio cultivation by the farmer's father, the average amount of time spent in seasonal migration by males in the household, the dominant caste of the household, household monetary poverty, and the number of members of the household of working age. The farm-related variables we selected were: available manpower, the amount of arable land owned, borrowed land, commercial agricultural activities (growing watermelons and livestock fattening), and the number of active household members with non-agricultural income. This model was tested using binary logistic regression on the STATA ${ }^{\circledR} 13.1$ software.

The sample created for the ESCAPE survey was designed to be representative for all of the 30 villages of the HDSS-Niakhar. To increase the sensitivity of the prediction model, we cleared the model (analysis of residuals), eliminating values that differed significantly from others (outliers) and those that excessively affected the model (leverage points and influencers). The overall adjusted and cleared model was shown to be quite robust (Hosmer-Lemeshow test) and had greater sensitivity, which increased to $77 \%$ after the sample was adjusted.

\section{Results}

Recovery of rainfall. Rainfall time series in the study zone (see Fig. 1a) show two distinct periods in rainfall evolution since the 1950s (See Fig. 1b). From 1950 to 1981, a rapid decrease in rainfall $(-15.64 \mathrm{~mm} /$ year $)$ was observed. In contrast, the recent period has seen a partial recovery of rainfall with a positive linear trend ranging between $+5.0 \mathrm{~mm} /$ year and $+7.8 \mathrm{~mm} /$ year depending on the rainfall station. Consequently, a $39 \%$ increase in rainfall was observed from 1982 to 2015 in the study zone. Following two dry years, 2006 and 2007, the trend of increased rainfall has risen even more sharply since 2008 , with precipitation up by an average of 4\% per year between the 1998-2007 and 2008-2015 periods (average accumulation of $420 \mathrm{~mm}$ and $590 \mathrm{~mm}$ per year, respectively). Similar rainfall regimes (levels and trends) have been observed throughout the Fatick department.

Such changes in rainfall are not an isolated feature of this location of Senegal but belongs to a large-scale recent change in rainfall observed in Senegal and in several Sahelian countries (Panthou et al., 2014; Salack et al., 2011). Using 83 rainfall station data, Salack et al. (2011) depicted a similar positive trend in rainfall amount in Senegal associated with some changes in the frequency and intensity of rainy events. In addition, this observed rainfall variability in Senegal fits very well with the decades-long evolution and rainfall trends in Central Sahel as depicted by Panthou et al. (2014), which computed the Standardised Precipitation Index (SPI) with data from 43 rainfall stations in Benin, Burkina Faso and Niger (See Fig. 1b). The correlation between the SPI in Central Sahel and the study zone rainfall time series from 1950 to 2015 is $R=0.94$.

To assess climate perceptions, individual questionnaire-based surveys were administered in 2014 to 1061 randomly selected farmers in the 30 villages of the HDSS-Niakhar. The questions covered climate characteristics both at the time of the survey and 20 years previously (in the mid-1990s). The responses from the rural populations in this area about recent rainfall trends revealed a close correlation between perceptions and observed rainfall. More than $96 \%$ of those surveyed were aware of the recent rainfall increase. The populations surveyed in Senegal clearly perceived the transition observed between a dry period 20 years ago and the present wet period (See Fig. S1). The drought-a major environmental problem two decades earlier for $65 \%$ of the population surveyed-has now become just a minor concern, with less than $3 \%$ considering it to be a problem affecting their area. The questions that support these results were: In your opinion, what are the main climate and environmental issues that most affect the area where you live now? In your opinion, what were the main climate and environmental issues that most affected the area where you live 20 years ago?

Resurgence of the cultivation of sanio millet. Evidence of responsive adaptation by farmers to the recent rainfall recovery they perceived was found with the re-emergence of the cultivation 

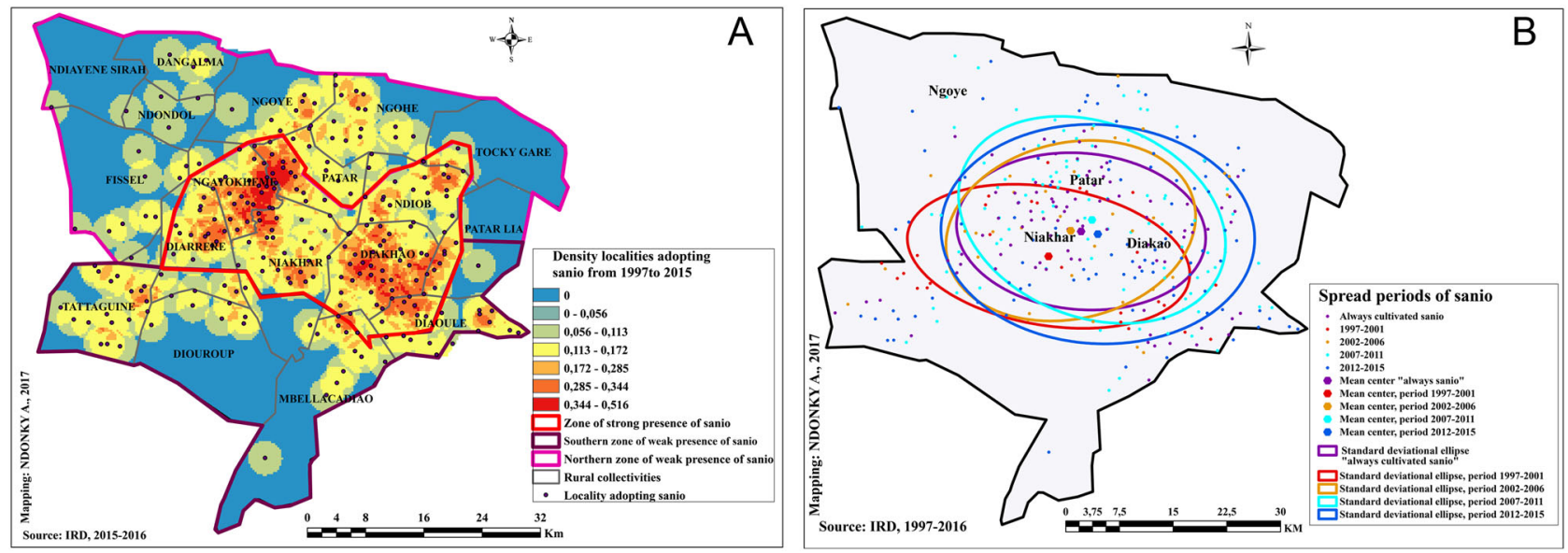

Fig. 2 Density of localities adopting sanio, 1997-2015 (a) and Spread of sanio (b). The density and diffusion estimate of the sanio are based on the 346 villages that cultivated sanio. In the study area, 319 other villages were surveyed, and no one said they had cultivated the sanio. The latter are not represented on both maps $2 a$ and $2 b$. a evaluates the density surface area of villages that cultivated sanio over the recent 1997-2015 period, using data mapped in $\mathbf{b}$. The density surface area of villages that had started growing sanio again was obtained from a raster grid that combined the point density at each pixel with nearby points. The three mains geographic sanio zones were identified by combining three methods: standard deviational ellipse, point density and hierarchical neighbourhood clusters. $\mathbf{b}$ is a map of the villages in the study zone by period of re-emergence of the cultivation of sanio millet. Villages that have never abandoned sanio cultivation in purple dots. The circles represent the standard deviational ellipses per sanio spread period and the points indicate the mean centres of these dissemination ellipses at different periods

of sanio millet in the study zone (See Fig. 2a). This type of pearl millet has higher water requirements and longer crop duration than the dominant cultivated crop, souna millet-a short cycle (80-day) variety better adapted to drought (Dancette, 1983). Focus groups, interviews and surveys with farmers revealed that while sanio millet was grown in the 1950s, it was abandoned by most farmers in the early 1980s, doubtless because of a succession of poor crops during the 1970s. The water deficit is the main reason cited by farmers for abandoning the cultivation of sanio millet (mentioned by $40 \%$ of the people surveyed; see Fig. S2), although other reasons were evoked by farmers that were not necessarily linked with drier conditions (insect and bird damage, soil fertility, lack of seeds).

In 2015 , we found that $50.4 \%$ of the 665 villages surveyed grew sanio millet. This cultivation primarily reappeared after 1997 , and especially in the years since 2008 ( 180 of 244 villages had resumed planting sanio) although farmers in 91 villages (14\%) claimed not to have ever abandoned sanio cultivation. This resurgence was unevenly distributed across the territory surveyed. As Fig. 2b shows, this grain was mainly planted in the central area of the study zone (around two nodes), where 64\% of villages reported having resumed growing sanio and $26 \%$ reporting they had never discontinued planting it (See Fig. 2b). In those areas, farmers justified the reintroduction of this millet by the better quality of its grain (better taste, more easily digested, more filling) and its stalks for forage, roofing and fences compared to souna millet (See Fig. S2). Conversely, only a minority of villages in both the northern and southern areas had resumed planting sanio (17\% in the north and $39 \%$ in the south), and very few had never stopped ( $4 \%$ in the north and $12 \%$ in the south).

The spreading of sanio remained low for the decades between 1997 and 2015. For each five-year periods, the centre of the elliptical area cultivated in sanio, as schematized in Fig. 2b, extended on average from 2 to $6 \mathrm{~km}$ compared to the previous period. Despite a small expansion of the sanio culture to the north between 2007 and 2011, the cultivation of this cereal spread mainly to the west (first period) and south-east (last period).

In the HDSS-Niakhar where we conducted individual surveys, sanio was grown in 27 of the 30 villages (90\%) in 2013. However, this practice was not common to all farmers, as only $25.4 \%$ of the
1061 surveyed had planted the grain that year. Furthermore, the cultivation of sanio millet is far from supplanting the cultivation of souna millet. In the HDSS-Niakhar, only 89 (14\%) of the 630 fields cultivated with sanio millet were sown with sanio alone. The majority were planted with a combination of souna and sanio with fewer rows of sanio, generally at a ratio of one row of sanio to five rows of souna. In total, sanio only represented $3 \%$ of all planted fields and $7.3 \%$ of the grain fields in the 30 villages in the HDSS-Niakhar (See Fig. S3) (Muller et al., 2015). This indicates that even though farmers prefer sanio millet and have perceived that the climate is now favourable for its cultivation, they are aware of the risk of only cultivating a more water-intensive crop under a variable climate environment and that planting several varieties of millet can shield them from the risks of an unstable rainy season.

A link between rainfall and the re-emergence of sanio millet. Clearly, the re-emergence of sanio millet is linked with rainfall variability (See Fig. 3a). We found that the incidence rate of villages adopting sanio millet is slightly correlated to past year rainfall throughout the study zone $\left(R^{2}=0.36\right)$. But we also found that the increase in annual rainfall accumulation strongly affects the resumption of sanio cultivation from north to south in this region. In the central area of the study zone, the annual incidence of villages adopting sanio increased 2.4 times more quickly than in the south and 4.2 times more quickly than in the north (calculated from adjusted regression coefficients). Annual rainfall better explains the expansion of sanio cultivation-albeit quite small-in the north $\left(R^{2}=0.76\right)$ than in the south $\left(R^{2}=0.53\right)$ or even in the centre $\left(R^{2}=0.56\right)$, where sanio has spread more extensively.

Across the entire study zone, more than 6.3 new villages adopt sanio millet per year when the average rainfall is around $415 \mathrm{~mm}$ by growing season and exceeds 25.6 villages per year when the rainfall averages between 580 and $620 \mathrm{~mm}$ by growing season (See Fig. 3a). The incidence of villages adopting sanio millet increases when there is more than $530 \mathrm{~mm}$ of annual rainfall in the centre of the study zone and more than $600 \mathrm{~mm}$ in the south (See Fig. 3b). 

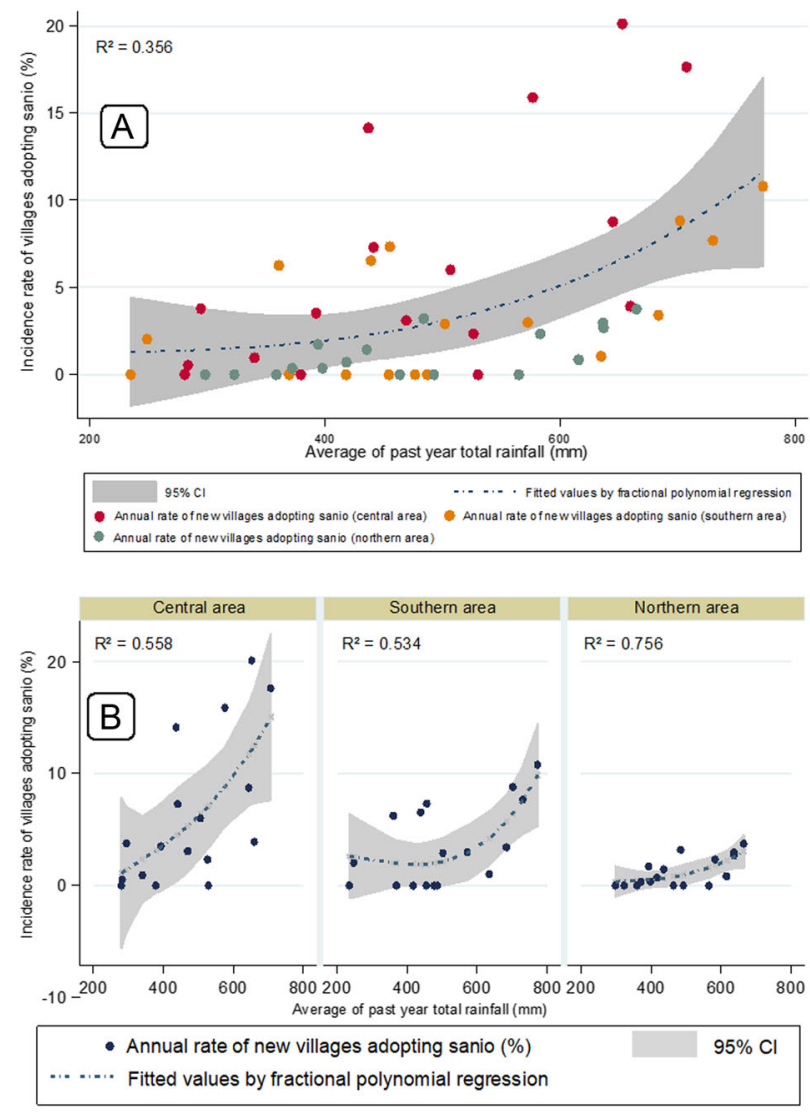

Graphs by zone

Fig. 3 Correlation between rainfall and sanio-a for the entire study zone and (b) by area. Figure 3 shows non-linear fitting between the incidence rate of villages adopting sanio millet and the average of past year total rainfall. The incidence rate indicates the number of new villages adopting sanio relative to the number of villages that have not adopted sanio millet (including the new villages). The average of past year total rainfall is the rainfall observed the year before the adoption of sanio millet. The fitted curve is calculated using a fractional polynomial regression with Stata $13.0^{\circledR}$. a shows the fitted curve for the entire study zone. $\mathbf{b}$ shows the fitted curve by geographic sanio zone

In order to investigate more deeply the quasi-simultaneity of two events (annual rainfall and the adoption of millet by villages), we apply event coincidence analysis (ECA) (Donges et al., 2016; Siegmund et al., 2017), a novel yet conceptually simple statistical method. For this, we consider: the years according to whether or not they exceeded a certain threshold of cumulative rainfall and the years when the proportion of village adopting millet culture were greater (or not) than the 65th percentile of the distribution of villages adopting millet, for a given territory. It is assumed that the first event will trigger the second, if the latter occurs within two years after an annual rainfall above the defined threshold. The percentage of years which, having exceeded the annual rainfall threshold, triggers in the next two years a strong conversion of villages to the cultivation of millet, sets the trigger rate.

Figure 4 shows the evolution of the trigger rate of a high adoption of sanio millet culture by the villages, according to different rainfall thresholds and for each area studied. Overall, the culture of sanio millet has spread more rapidly and more strongly (in absolute numbers) in the central part of the study area compared to the northern and southern villages (See Fig. 3b). However, the same rainfall amount is related to a comparable village trigger rate of sanio millet diffusion (See Fig. 4). Beyond
$500 \mathrm{~mm}$ of annual rain, the sanio culture is adopted, in nearly $75 \%$ of the rainy years, by a substantial proportion (above the 65th percentile) of villages. With more than $600 \mathrm{~mm}$ of annual rainfall, it is almost $100 \%$ of the very rainy years that trigger this same level of adoption of the Sanio among the late village adopters. In-below of $500 \mathrm{~mm}$, trigger coincidence rates are more dispersed between zones, but are also overall less reliable at the $5 \%$ error threshold.

Simulations of crop yield (See Fig. 5a) and above-ground biomass (See Fig. $5 \mathrm{~b}$ ) of souna and sanio millet were performed using the SARRA-H crop model at the Bambey location. Crop yield simulations confirmed that even modest yields of sanio millet could not have been obtained during the 1970s and 1980s and most of the 1990s (See Fig. 5a). The synchronicity between the time series of crop yields and the evolution of the adoption rate of sanio by farmers is shown in Fig. 4a. The cultivation of this crop only became truly feasible again at the beginning of the 2000s, which corresponds roughly to the time it was re-adopted by farmers (See bars in Fig. 5a). In contrast, souna millet cultivation remained possible, but, of course, experienced several very bad years during the severe droughts of the 1980s. This can be explained by the different response of the crops to rainfall fluctuations in the crop model. The simulated crop yield of sanio millet is highly correlated to annual rainfall $(R=0.80)$ while souna millet is less responsive, with a correlation of $R=0.56$ between crop yield and rainfall (See Fig. 5c). Souna millet is less sensitive to drought with higher yield than sanio millet when rainfall is below $600 \mathrm{~mm}$ per cycle.

Although the simulated crop yield of sanio millet clearly increases from the end of the 1990s, it is still more variable than that of the souna variety. The standard deviation of sanio millet yield is $986 \mathrm{~kg} / \mathrm{ha}$ between 1995 and 2015 and only $663 \mathrm{~kg} / \mathrm{ha}$ for souna. This high variability might explain why most farmers continue to grow the two crops together instead of investing everything in a single risky cultivation.

In contrast, we found in our simulations that it has always been possible to achieve good straw production with sanio millet (See Fig. 5b). This biomass production is usually greater than that of souna under the same management conditions because the crop is taller, and its cycle is about one month longer. This might explain why a significant number of farmers never abandoned the sanio cultivation (See Fig. 2b).

\section{Discussion}

This study confirms the observations already made by many researchers: smallholder farmers in the Sahel have adapted to changing climatic conditions over the period 1997-2015. They are well aware of the impacts of climate change on their agricultural production and they adapt their practices to try to reduce the negative effects or seize the opportunities of climate change (Altieri and Nicholls, 2017; Conway, 2011; Barbier et al., 2009; Mertz et al., 2010; West et al., 2008). The studied response to a favourable climate change-just like it would be to a climaterelated shock-is responsive in nature, on the initiative of farmers and rooted in village community traditions (Crane et al., 2011). Finally, it is a strategy of risk reduction through crop diversification, a prevalent practice in Africa (Agrawal, 2010; Burhnam and Ma, 2016).

Analyses of various databases show that the cultivation of sanio, a long-cycle millet, which had nearly disappeared from the Fatick region for nearly a quarter of a century, has once again spread throughout the study zone (in the centre of the Fatick department). The resumption of sanio cultivation is clearly associated with increased rainfall, including the crossing of the $550-600 \mathrm{~mm} /$ year threshold starting from 2008. These 


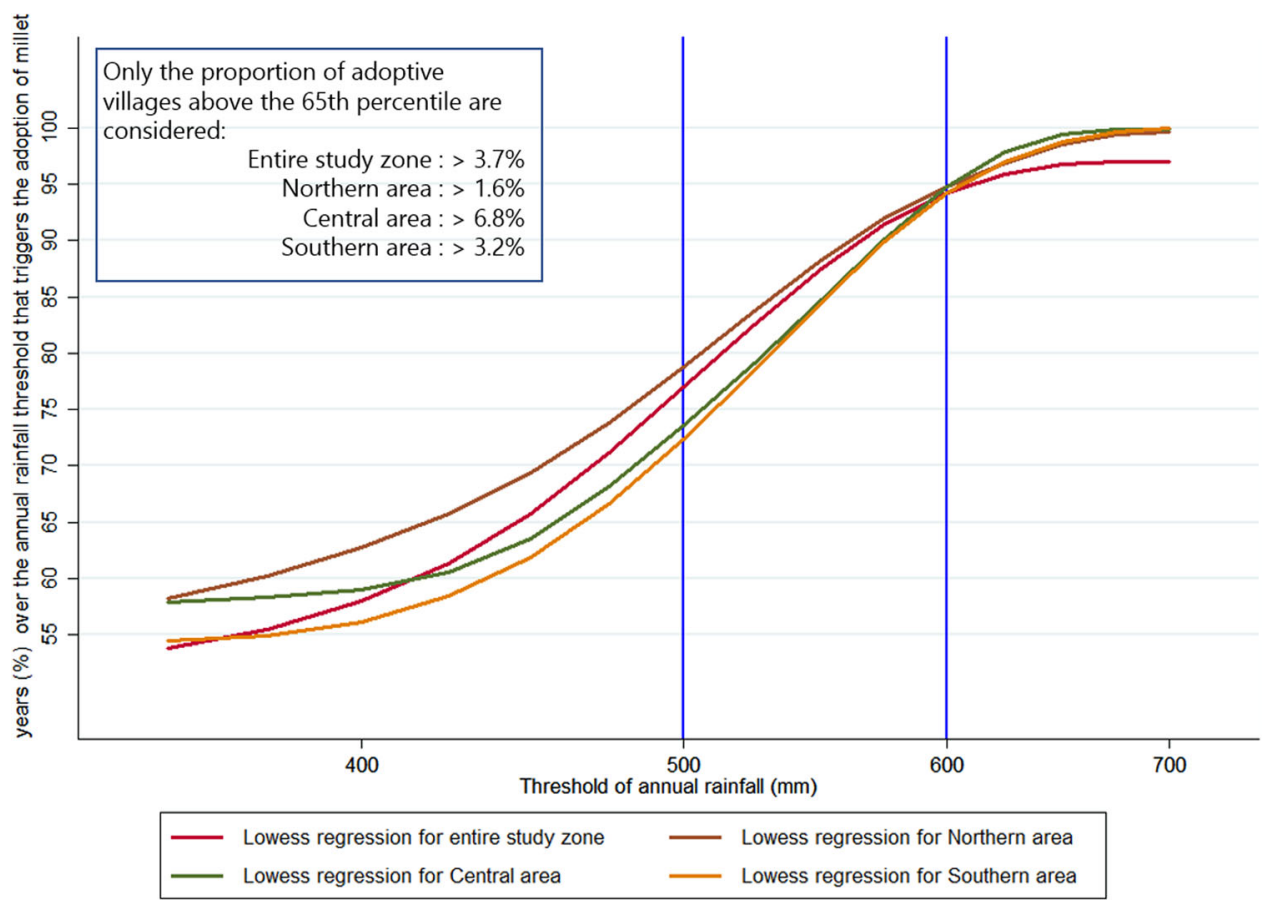

Fig. 4 Percentage of years over the annual rainfall threshold that triggers the adoption of millet by area for the 1997-2015 period. The indicator in the graph was calculated using the event coincidence analysis (Package CoinCalc) under R. The smoothed curve was calculated by local regression (lowess). This indicator represents the trigger coincidence rate for the adoption of millet by the villages, according to an annual rainfall threshold. For each area, a rainy year is considered a stimulus that triggers the adoption of millet, if the proportion of new villages adopting the cereal, in one of the following two years, exceeds the 65th percentile of the distribution of millet-growing villages. For example, about $95 \%$ (trigger rate) of years ( $t$ ) exceeding 600 mm of annual rainfall triggered the adoption of millet by at least $6.8 \%$ of new villages in the central area, at year $\mathrm{t}+1$ or $\mathrm{t}+2$. Starting from $500 \mathrm{~mm}$ of annual rainfall, all trigger rates are significant at the $5 \%$ threshold. Before this level of annual rainfall $(500 \mathrm{~mm}), 46 \%(11 / 24)$ of the calculated rates are not significant
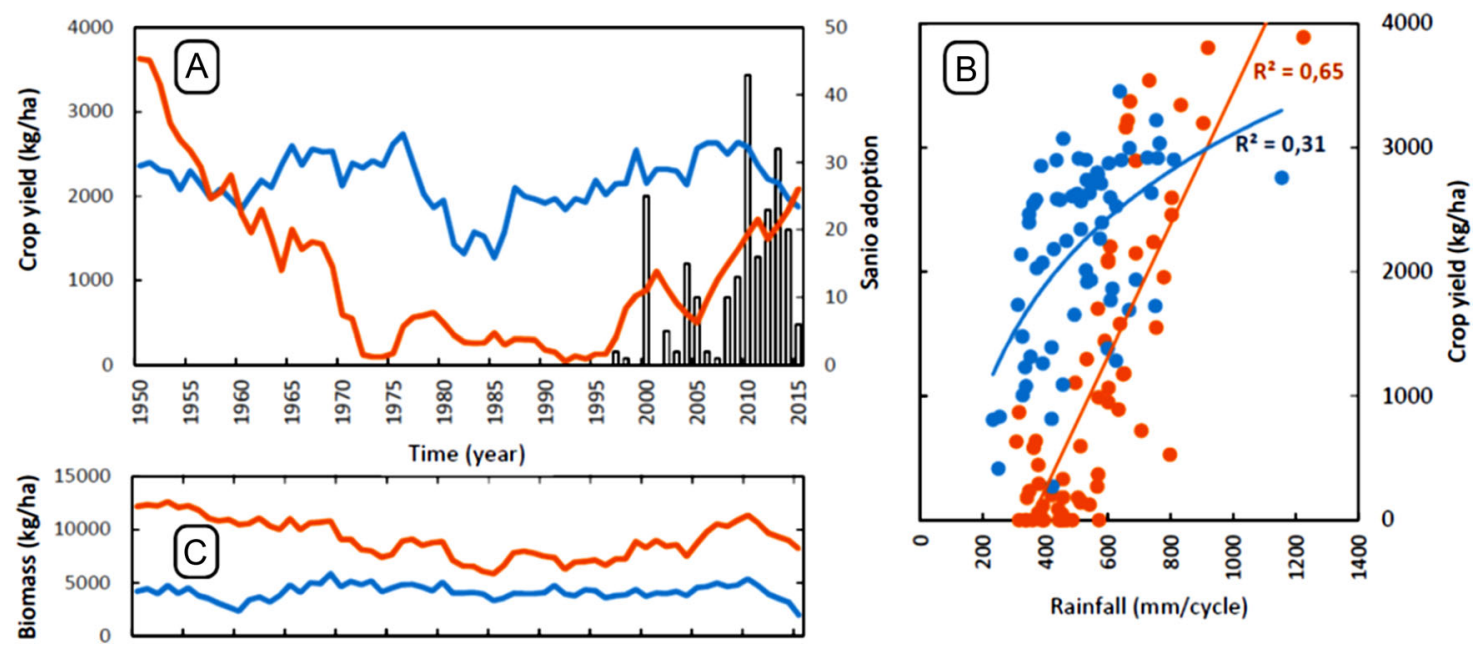

Fig. 5 Crop simulation of souna and sanio millet. a crop yield ( $\mathrm{kg} / \mathrm{ha}$ ) and (b) above-ground biomass ( $\mathrm{kg} / \mathrm{ha}$ ) of souna (blue line) and sanio (red line) millet simulated by the SARRA-H crop model at the Bambey location. A five-year moving average was applied to all time series. The bars represent the adoption rate of sanio by farmers, which is the number of new villages adopting sanio millet each year in the HDSS-Niakhar. c Relationship between crop yield ( $\mathrm{kg} / \mathrm{ha}$ ) and annual rainfall (mm/year) at the Bambey location. A logarithmic fit has been applied for souna millet simulations (blue) and a linear fit has been applied for sanio millet simulations (red). The coefficient of determination $\left(R^{2}\right)$ of those two fits is 0.3102 and 0.6449 for souna millet and sanio millet, respectively

observations are corroborated by our simulations and by the agronomic experiments conducted in 1976/1977 in our study area by C. Dancette et al. $(1979,1983)$, who estimated that the water requirements for 120-day millets (like sanio) were at least $562-657 \mathrm{~mm}$.

The recovery of sanio culture is not a strictly opportunistic practice. It also falls within a strategy to reduce the risks and increase cereal production. In the area covered by the HDSSNiakhar, 2014 was a dry year, with a decrease of $200 \mathrm{~mm}$ of rain compared to 2013, and with a dry spell of 31 days between July and August (rainy season). This rain shortage led to a $34 \%$ reduction of the number of sanio producers. However, the great majority of growers continued to produce sanio, because this crop is better suited to late rainfall in the season, and that it was able to 
partly compensate the poor harvest of the short-cycle millet (souna, in Wolof). Thirty-five percent of farmers felt that using sanio allowed them to diversify their crops and thus ensure better food security (See Fig. S2). Therefore,the double cereal crop (souna and sanio) over the growing season limited the risks associated with a high rainfall variability during the rainy season.

Although all the farmers living in the study zone's villages were subjected to the same climate conditions, and generally aware of the increase in annual rainfall (Kosmowski et al., 2015), not all of them resumed planting sanio millet, nor did they do it at the same degree. Sanio is only densely planted in the central area of our study zone (where 2 out of 3 villages resumed growing sanio). In the south, and to an even greater extent in the north, this grain remains much less common, grown in 1 out of 3 villages in the south and only 1 out of 5 villages in the north (See Fig. 2a). Thus, while the recovery of higher rainfalls explains why sanio was once again being planted, it does not explain its uneven adoption.

One reason for these geographic differences is that sanio farming is an expression of traditional practices for a variety of millet that is typical of the agricultural system and rural identity of the Sereer farmers in the Fatick region (Pelissier, 1966). In the villages of the central study zone where sanio cultivation is the densest, $27 \%$ of village key informants reported that some farmers in the village never stopped growing this long-cycle millet even during major droughts, as opposed to $12 \%$ in the south and $4 \%$ in the north. This rustic variety of millet has doubtless been preserved by a handful of farmers. A few of them reported that they had planted sanio in their compound yard plots, where the plants received runoff domestic water. So they were able to produce stalks and grains even in dry years. The farmers in the central study zone invested a lot in sanio production, some even before rainfall levels reached the $550 \mathrm{~mm} /$ year threshold (See Fig. 3b). Our survey data from farm operators further revealed that those whose fathers grew sanio in the past were nearly three times more likely to grow it in 2013 than those without this family tradition $(\mathrm{OR}=2.72 ; p=0.000$, See Table S4) (Muller et al., 2015).

Sanio cultivation is an adaptation which seizes a climatic opportunity. It therefore does not seek to address a shortage, but to mitigate risks-those associated with intra-annual climate variability-and increase food productions. More rainfall at the end of the agricultural season allowed farmers to reduce somewhat their vulnerability and reconnect with an ancient cropping system. But due to the low financial and technical means of the vast majority of peasants, this climate opportunity has not led to a transformation of agriculture. The resurgence of rainfall has sometimes promoted commercial development of agriculture, but these market exchange adaptations (Agrawal, 2010) have remained insufficient to transform the regional economy. Watermelon in the Fatick and Kaolack regions, and rainfed rice and corn in the Kaolack region, are all agricultural products that thrive when rainfall increases, especially at the end of the rainy season. Unlike sanio millet, these crops generally require some investment (seed, fertiliser, phytosanitary products, equipment, etc.) as well as the mastery of cultivation techniques. Moreover, the cultivation of these commercial products has expanded in parallel with urban consumption and livestock feed factories and is supported by active farmer organisations and structured value chains.

In the HDSS-Niakhar study area, some high-income farming practices appear to limit the cultivation of sanio, such as cattle fattening $(\mathrm{OR}=0.66 ; p=0.081)$ and watermelon culture $(\mathrm{OR}=0.57 ; p=0.079)$, although statistical associations are significant to less than $10 \%$ (See Table S4). The opposite choice between sanio farming and commercial practices can also be assumed by the negative effect of the number of farmers managing plots per farm on sanio cultivation. Generally, apart from the farm head, family members work on plots for their own benefit (sales of production). Therefore, the greater the number of farmers in the same farm, the less likely the farm will produce sanio $(\mathrm{OR}=0.91 ; p=0.008)$. Conversely, farmers are more likely to plant sanio as they had a large amount of farmland $(\mathrm{OR}=1.14$; $p=0.000)$ or if they borrowed land $(\mathrm{OR}=2.08 ; p<0.001)$ (See Table S4). The opposition between a market exchange adaptation, which requires a greater capital investment, and adaptation based on sanio farming is finally shown by the fact that households that are the poorest monetarily are those that grow sanio ( $\mathrm{OR}=2.03 ; p=0.000)$. In 2014 , the monetary poverty threshold was estimated at 479 FCFA $\left(1 \mathrm{US}^{1}{ }^{1}\right)$ per day per adult, in the HDSS-Niakhar, and half of the population (52\%) were poor. Thus, poverty is not a barrier to this diversification adaptation because no additional investment or technical expertise is needed to grow sanio. But this non-commercial food production is not a lever for wealth creation, contrary to what may have been observed from other adaptations (Ali and Erenstein, 2017).

Unlike climate shock, climate opportunity does not weaken farmers' adaptability. However, it does not increase it further. It is at most a positive stimulus that can (or not) promote adaptations (diversification, trade exchanges), depending on the initial socioeconomic status of farmers. Moreover, if specific climate conditions are necessary to trigger a process of transformation in the case of rainfed agriculture, it is the market that is often the most powerful driver to transform the local economy and improve economic and technical capital, and land tenure of farmers. The cultivation of a variety of long-cycle millet is not an innovation to transform the cultural system and the sereer agricultural economy. It is at best a non-erosive adaptation, accessible to the poorest farmers, well integrated into the traditional cultural sereer system and which improves the household's food security.

\section{Conclusion}

In West Africa, as elsewhere in the world, the adaptation of agriculture to climate change is not new. Mainly rainfed, smallscale African agriculture is highly subject to climate change and variability, compelling farmers and their families to implement adaptation strategies to maintain their standards of living and agricultural production, fodder, firewood and building materials. Even in the absence of economic and technical means, African farmers are therefore neither necessarily nor totally vulnerable to climate events. However, their answers must also deal with all the constraints, uncertainties and limitations that reduce their ways of acting. This results in minimal adaptations, sometimes ecologically sustainable and rarely transformational.

In Central Senegal, the combined cultures of short-and longcycle millets improve the food security of some farmers and protect them against poor distribution of rainfall during the agricultural season. For example, the cultivation of watermelon, by other farmers allows trading exchanges, the modernisation of production techniques and reduction of economic vulnerability. The balanced association on the farm of staple and cash crops has long been a principle of the sereer agrosystem that participated in both the ecological maintenance of soil fertility and emergence of agricultural innovation. However, increased rainfall in this poor area may, while developing new opportunities, also deteriorate the traditional agro-system by upsetting the fragile balance between staple and cash crops.

This study illustrates the capacity of farmers in the Sahel to adapt to climate fluctuations. However, more research would be needed to fully understand the limits of such responsive adaptation to face radical climate changes. Indeed, warm and drought conditions in the west Sahel simulated by climate models with the increase in greenhouse gas emissions have no analogy with the 
past we can draw on to make predictions for the future (Sultan et al., 2013). Farmers' spontaneous adaptations per se may not be enough to limit the negative effects of climate changes. Current practices may need to be combined with proactive, anticipatory adaptation (Hertel and Lobell, 2014). A positive adaptation strategy would incorporate new agricultural technologies to improve breeding more resilient crop varieties and innovating water harvesting techniques. Another important factor to enhance adaptation to climate change is related to institutional changes that affect markets and policies. The smallholder farmers from the Sahel should be able to access fertiliser subsidies, crop insurance, credits and weather and climate forecast services to reach their maximum potential to adapt to future climate conditions.

\section{Data availability}

The datasets generated and analysed during the current study are available from the corresponding author on reasonable request.

Received: 18 June 2018 Accepted: 12 June 2019

Published online: 23 July 2019

\section{Notes}

1 Exchange rate on 01/01/2014.

\section{References}

Adejuwon JO (2005) Food crop production in Nigeria. I. Present effects of climate variability. Clim Res 30(1):53-60

Adger WN, Huq S, Brown K, Conway D, Hulme M (2003) Adaptation to climate change in the developing world. Prog Dev Stud 3(3):179-195

Agrawal A (2010) Local institutions and adaptation to climate change. In:Mearns $\mathrm{R}$, Norton A (eds) Social dimensions of climate change: equity and vulnerability in a warming world, 2. World Bank, Washington, DC, p 173-178

Ali A, Erenstein O (2017) Assessing farmer use of climate change adaptation practices and impacts on food security and poverty in Pakistan. Clim Risk Manag 16:183-194

Altieri MA, Nicholls CI (2017) The adaptation and mitigation potential of traditional agriculture in a changing climate. Clim Change 140(1):33-45

Barbier B, Yacouba H, Karambiri H, Zoromé M, Somé B (2009) Human vulnerability to climate variability in the Sahel: farmers' adaptation strategies in northern Burkina Faso. Environ Manag 43(5):790-803

Baron C, Sultan B, Balme M, Sarr B, Traore S, Lebel T, Dingkuhn M (2005) From GCM grid cell to agricultural plot: scale issues affecting modelling of climate impact. Philos Trans R Soc B: Biol Sci 360(1463):2095-2108

Bationo A, Kihara J, Waswa B, Ouattara B, Vanlauwe B (2005) Integrated soil fertility management technologies for sustainable management of sandy Sahelian soils. In: Proceedings of the International Symposium on "The management of tropical sandy soils for sustainable agriculture- a holistic approach for sustainable development of problem soils in the tropics" November 2005. Khon Kaen, Thailand

Berrang-Ford L, Ford JD, Paterson J (2011) Are we adapting to climate change? Glob Environ change 21(1):25-33

Burnham M, Ma Z (2016) Linking smallholder farmer climate change adaptation decisions to development. Clim Dev 8(4):289-311

Conway D (2011) Adapting climate research for development in. Afr Wiley Interdiscip Rev 2(3):428-450

Crane TA, Roncoli C, Hoogenboom G (2011) Adaptation to climate change and climate variability: the importance of understanding agriculture as performance. NJAS-Wagening J Life Sci 57(3-4):179-185

Dancette C (1983) Estimation des besoins en eau des principales cultures pluviales en zone soudano-sahélienne. L'Agron Trop 38(4):281-294

Dancette C, Hamon G, Vachaud G (1979) Etude comparée de la dynamique de l'eau en sol sableux nu et cultivé. Modalités d'alimentation hydrique du mil et de l'arachide en conditions pluviales déficitaires, au Sénégal. In: Isotopes and radiation in research on soil-plant relationships; proceedings of an International Symposium on the Use of Isotopes and Radiation in Research on Soil-Plant Relationships, International Atomic Energy Agency and the Food and Agriculture Organization of the United Nations, Colombo, 11-15 December 1978. International Atomic Energy Agency, Vienna p. 213-234
Dingkuhn M, Miezan KM (1995) Climatic determinants of irrigated rice performance in the Sahel - II. Validation of photothermal constants and characterization of genotypes. Agric Syst 48:411-433

Dingkuhn M, Baron C, Bonnal V, Maraux F, Sarr B, Sultan B, Clopes A, Forest F (2003) Decision support tools for rainfed crops in the Sahel at the plot and regional scales. In: Decision support tools for smallholder agriculture in SubSaharan Africa: a practical guide. Struif Bontkes T, Wopereis M (eds) IFDC, CTA. Muscle Shoals: IFDC pp. 127-139

Dingkuhn M, Kouressy M, Vaksmann M, Clerget B, Chantereau J (2008) A model of sorghum photoperiodism using the concept of threshold-lowering during prolonged appetence. Eur J Agron 28(2):74-89

Donges JF, Schleussner CF, Siegmund JF, Donner RV (2016) Event coincidence analysis for quantifying statistical interrelationships between event time series. Eur Phys J Spec Top 225(3):471-487

Eriksen S, O'Brien K, Rosentrater L (2008) Climate change in eastern and southern Africa: impacts, vulnerability and adaptation. GECHS Rep 2008(1):27.

Fankhauser S, Smith JB, Tol RS (1999) Weathering climate change: some simple rules to guide adaptation decisions. Ecol Econ 30(1):67-78

Findley SE (1994) Does drought increase migration? A study of migration from rural Mali during the 1983-1985 drought. Int Migr Rev 28:539-553

Henry S, Schoumaker B, Beauchemin C (2004) The impact of rainfall on the first out-migration: A multi-level event-history analysis in Burkina Faso. Popul Environ 25(5):423-460

Hertel TW, Lobell DB (2014) Agricultural adaptation to climate change in rich and poor countries: Current modeling practice and potential for empirical contributions. Energy Econ 46:562-575

Huq S, Reid H (2004) Mainstreaming adaptation in development. IDS Bull 35 (3):15-21

IPCC (2014) Climate Change 2014: Impacts, Adaptation, and Vulnerability. Part A: Global and Sectoral Aspects. In: Field CB, Barros VR, Dokken DJ, Mach KJ, Mastrandrea MD, Bilir TE, Chatterjee M, Ebi KL, Estrada YO, Genova RC, Girma B, Kissel ES, Levy AN, MacCracken S, Mastrandrea PR, White LL (eds) Contribution of Working Group II to the FifthAssessment Report of the Intergovernmental Panel on Climate Change. Cambridge University Press, Cambridge, New York, p. 1132

Kates RW, Travis WR, Wilbanks TJ (2012) Transformational adaptation when incremental adaptations to climate change are insufficient. Proc Natl Acad Sci 109(19):7156-7161

Knox J, Hess T, Daccache A, Wheeler T (2012) Climate change impacts on crop productivity in Africa and South Asia. Environ Res Lett 7(3):034032

Kosmowski F, Lalou R, Sultan B, Ndiaye O (2015) Observations et perceptions des changements climatiques. Analyse comparée dans trois pays d'Afrique de l'Ouest. In:Sultan B, Lalou R, Oumarou A, Sanni MA, Soumaré A (eds) Les sociétés rurales face aux changements environnementaux en Afrique de l'Ouest. Editions de l'IRD, Paris, p. 89-110

Kouakou PK, Muller B, Guissé A, Yao RN, Fofana A, Cissé N (2013) Étude et prise en compte en modélisation de l'effet de la latitude sur la réponse à la photopériode chez divers génotypes de mil (Pennisetum glaucum (L.) R. Br.) du Sénégal. J Appl Biosci 67:5289-5301

Kouressy M, Dingkuhn M, Vaksmann M, Heinemann AB (2008) Adaptation to diverse semi-arid environments of sorghum genotypes having different plant type and sensitivity to photoperiod. Agric For Meteorol 148(3):357-371

Kristjanson P, Neufeldt H, Gassner A, Mango J, Kyazze FB, Desta S, Coe R (2012) Are food insecure smallholder households making changes in their farming practices? Evidence from East Africa. Food Secur 4(3):381-397

Lalou R, Delaunay V (2017) Seasonal migration and climate change in rural Senegal. A form of adaptation or failure to adapt ? In: Sultan B, Lalou R, Oumarou A, Sanni MA, Soumare A (eds) Rural societies in the face of climate and environmental changes in West Africa. IRD Editions, Paris, p 269-293

Malik A, Qin X, Smith SC (2010) Autonomous adaptation to climate change: a literature review. Institute for International Economic Policy Working Paper Series. The George Washington University, Washington, DC, p. 24

Mertz O, Mbow C, Reenberg A, Diouf A (2009) Farmers' perceptions of climate change and agricultural adaptation strategies in rural Sahel. Environ Manag 43(5):804-816

Mertz O, Mbow C, Nielsen J, Maiga AY, Diallo D, Reenberg A, Ouattara I (2010) Climate factors play a limited role for past adaptation strategies in West Africa. Ecol Soc 15(4):25. http://www.ecologyandsociety.org/vol15/iss4/art25/

Mishra A, Hansen JW, Dingkuhn M, Baron C, Traoré SB, Ndiaye O, Ward MN (2008) Sorghum yield prediction from seasonal rainfall forecasts in Burkina Faso. Agric For Meteorol 148(11):1798-1814

Muller B, Lalou R, Kouakou P, Soumare MA, Bourgoin J, Dorego S, Sine B (2015) Le retour du mil sanio dans le Sine: une adaptation raisonnée à l'évolution climatique. In: Sultan B, Lalou R, Oumarou A, Sanni MA, Soumaré A (eds) Les sociétés rurales face aux changements environnementaux en Afrique de l'Ouest. Editions de l'IRD, Paris, p. 377-401

Panthou G, Vischel T, Lebel T (2014) Recent trends in the regime of extreme rainfall in the Central Sahel. Int J Climatol 34(15):3998-4006 
Parry M, Parry ML, Canziani O, Palutikof J, Van der Linden P, Hanson C (eds) (2007) Climate change 2007-impacts, adaptation and vulnerability: Working group II contribution to the fourth assessment report of the IPCC, Vol. 4, Cambridge University Press, UK

Pelissier P (1966) Les paysans du Sénégal. Les civilisations agraires du Cayor à la Casamance. Imprimerie Fabrègue, Saint- Yrieix

Penning de Vries FWT, Jansen DM, ten Berge HFM, Bakema A (1989) Simulation of ecophysiological processes of growth in several annual crops, Vol. 29, International Rice Research Institute Pudoc, Wageningen, Netherlands

Rammig A, Wiedermann M, Donges JF, Babst F, Von Bloh W, Frank D, Mahecha MD (2015) Coincidences of climate extremes and anomalous vegetation responses: comparing tree ring patterns to simulated productivity. Biogeosciences 12(2):373-385

Rickards L, Howden SM (2012) Transformational adaptation: agriculture and climate change. Crop Pasture Sci 63(3):240-250

Rippke U, Ramirez-Villegas J, Jarvis A, Vermeulen SJ, Parker L, Mer F, Howden M (2016) Timescales of transformational climate change adaptation in subSaharan African agriculture. Nat Clim Change 6(6):605

Roudier P, Sultan B, Quirion P, Berg A (2011) The impact of future climate change on West African crop yields: What does the recent literature say? Glob Environ Change 21(3):1073-1083

Salack S, Muller B, Gaye AT (2011) Rain-based factors of high agricultural impacts over Senegal. Part I: integration of local to sub-regional trends and variability. Theor Appl Climatol 106(1-2):1-22

Siegmund JF, Sanders TG, Heinrich I, van der Maaten E, Simard S, Helle G, Donner RV (2016a) Meteorological drivers of extremes in daily stem radius variations of beech, oak, and pine in northeastern Germany: an event coincidence analysis. Front Plant Sci 7:733

Siegmund JF, Wiedermann M, Donges JF, Donner RV (2016b) Impact of temperature and precipitation extremes on the flowering dates of four German wildlife shrub species. Biogeosciences 13(19):5541-5555

Siegmund JF, Siegmund N, Donner RV (2017) CoinCalc-A new R package for quantifying simultaneities of event series. Comput Geosci 98:64-72

Sinclair TR, Muchow RC (2000) Radiation use efficiency. Adv Agron 65:215-265

Smit B, Wandel J (2006) Adaptation, adaptive capacity and vulnerability. Glob Environ change 16(3):282-292

Suhrke A (1994) Environmental degradation and population flows. J Int Aff 47 (2): 473

Sultan B, Gaetani M (2016) Agriculture in West Africa in the twenty-first century: climate change and impacts scenarios, and potential for adaptation. Front plant Sci 7:1262

Sultan B, Baron C, Dingkuhn M, Sarr B, Janicot S (2005) Agricultural impacts of large-scale variability of the West African monsoon. Agric For Meteorol 128 (1-2):93-110

Sultan B, Guan K, Kouressy M, Biasutti M, Piani C, Hammer GL, Lobell DB (2014) Robust features of future climate change impacts on sorghum yields in West Africa. Environ Res Lett 9(10):104006

Sultan B, Roudier P, Quirion P, Alhassane A, Muller B, Dingkuhn M, Baron C (2013) Assessing climate change impacts on sorghum and millet yields in the Sudanian and Sahelian savannas of West Africa. Environ Res Lett 8 (1):014040
Thomas DS, Twyman C, Osbahr H, Hewitson B (2007) Adaptation to climate change and variability: farmer responses to intra-seasonal precipitation trends in South Africa. Clim Change 83(3):301-322

Tschakert P (2007) Views from the vulnerable: understanding climatic and other stressors in the Sahel. Glob Environ Change 17(3-4):381-396

West CT, Roncoli C, Ouattara F (2008) Local perceptions and regional climate trends on the Central Plateau of Burkina Faso. Land Degrad Dev 19 (3):289-304

Willmott CJ (1982) Some comments on the evaluation of model performance. Bulletin of the American Meteorological Society 63(11):1309-1313

\section{Acknowledgements}

We thank G. Panthou and T. Vischel for providing us SPI time series. This work has been funded by the French National Research Agency (ANR) through the ESCAPE project (ANR-10-CEPL-005) and the NERC/DFID Future Climate For Africa programme under the AMMA-2050 project, grant number NE/M020126/1.

\section{Author contributions}

$\mathrm{RL}, \mathrm{BS}, \mathrm{BM}$ and AN designed research; RL, BM and AN conducted field surveys; BM performed the crop simulations; AN performed maps and spatial analyses, RL, BS, BM and $\mathrm{AN}$ analysed data; and RL and BS wrote the paper.

\section{Additional information}

The online version of this article (https://doi.org/10.1057/s41599-019-0288-8) contains supplementary material, which is available to authorized users.

Competing interests: The authors declare no competing interests.

Reprints and permission information is available online at http://www.nature.com/ reprints

Publisher's note: Springer Nature remains neutral with regard to jurisdictional claims in published maps and institutional affiliations.

(c) (i) Open Access This article is licensed under a Creative Commons Attribution 4.0 International License, which permits use, sharing, adaptation, distribution and reproduction in any medium or format, as long as you give appropriate credit to the original author(s) and the source, provide a link to the Creative Commons license, and indicate if changes were made. The images or other third party material in this article are included in the article's Creative Commons license, unless indicated otherwise in a credit line to the material. If material is not included in the article's Creative Commons license and your intended use is not permitted by statutory regulation or exceeds the permitted use, you will need to obtain permission directly from the copyright holder. To view a copy of this license, visit http://creativecommons.org/ licenses/by/4.0\%

(C) The Author(s) 2019 